\title{
Characteristics of Computerized Neuropsychologic Test According to the Location of Aneurysmal Subarachnoid Hemorrhage
}

\author{
Seung Don Yoo, M.D., Ph.D., Dong Hwan Kim, M.D., Ph.D., Gook Ki Kim, M.D., Ph.D., Jihea Bark, M.D.
}

Department of Physical Medicine \& Rehabilitation, College of Medicine, Kyung Hee University, Seoul 134-727, Korea

Objective To evaluate characteristics of cognitive impairments according to the location of aneurysmal subarachnoid hemorrhage (SAH) using a computerized neuropsychological test (CNT).

Method A total of 211 patients were transferred to our rehabilitation department after becoming neurologically stable following aneurysmal SAH. Twenty four of the 211 patients met the inclusion criteria and participated in a screening test using the mini-mental state examination (MMSE). Twenty patients with a MMSE score $<26$ were followed prospectively with a CNT and Beck depression inventory (BDI). Eleven patients had anterior communicating artery ( $\mathrm{ACoA})$ aneurysms and the other 9 had middle cerebral, internal carotid or posterior communicating artery aneurysms.

Results There were no differences in age, education, Hunt and Hess grade, or Fisher grade between the patients with ACoA aneurysmal SAH compared to patients with other aneurysmal SAH. In patients with ACoA aneurysmal $\mathrm{SAH}$, scores of BDI ( $\mathrm{p}=0.020)$, verbal learning test were lower than those of other aneurysmal SAH patients. In contrast, patients with non-ACoA aneurysmal SAH took significantly more time in auditory $(\mathrm{p}=0.025)$ and visual continuous performance tests $(\mathrm{p}=0.028)$. The cognitive deficit following aneurysmal SAH could be characterized by its location using CNT.

Conclusion Using CNT in aneurysmal SAH patients could be a useful tool for evaluating the characteristics of cognitive impairment and planning rehabilitation programs according to each characteristic.

Key Words Aneurysmal subarachnoid hemorrhage, Computerized neuropsychological test (CNT), Cognitive impairment

Received May 17, 2010; Accepted August 18, 2010

Corresponding author: Jihea Bark

Department of Physical Medicine \& Rehabilitation, College of Medicine, Kyung Hee University Hospital at Gangdong, 418, Bangadari-gil, Kangdong-gu, Seoul 134-727, Korea

Tel: +82-2-440-7155, Fax: +82-2-440-7260, E-mail: pure0111@hotmail. com

(ㄷ) This is an open-access article distributed under the terms of the Creative Commons Attribution Non-Commercial License (http://creativecommons.org/ licenses/by-nc/3.0) which permits unrestricted noncommercial use, distribution, and reproduction in any medium, provided the original work is properly cited. Copyright $\odot 2011$ by Korean Academy of Rehabilitation Medicine

\section{INTRODUCTION}

Subarachnoid hemorrhage (SAH) from a ruptured intracranial aneurysm accounts for up to $5 \%$ of all strokes, ${ }^{1}$ occurs at a relatively young age, ${ }^{2}$ and carries a poor prognosis for survival despite improvements in medical care for these patients. ${ }^{3}$ Although most survivors are free of physical handicap, but up to $50 \%$ remain 
permanently disabled because of cognitive dysfunction. ${ }^{1}$ Many of them have impairments in verbal and nonverbal memory, visual perception and construction, information processing speed, and executive function. ${ }^{4}$ Cognitive and psychological problems often occur in patients with SAH and reduce health-related quality of life, ${ }^{5}$ life satisfaction, ${ }^{6}$ return to work,${ }^{6,7}$ and engagement in social activities. ${ }^{7}$ The fact that $50 \%$ of patients who were previously employed do not return to the same level of work after SAH attests to the devastating nature of these deficits. ${ }^{6,7}$

Reports on different patterns of cognitive deficit, depending on the site of the aneurysm, are inconsistent. ${ }^{8,9}$ Different patterns may be present in patients with aneurysmal SAH in identical locations. ${ }^{10}$ Earlier studies which explored cognitive deficits after SAH from the anterior communicating artery (ACoA) described amnesia, personality changes, and confabulation as the main symptoms, ${ }^{11-15}$ and damage to particular anterior cerebral structures was a suspected cause. ${ }^{13,14,16}$ However, other studies did not find specific deficits in ACoA patients, and a more diffuse pattern of brain damage was thought to be responsible for the deficits. ${ }^{17-19}$

Accurate cognitive assessment of patients after aneurysmal SAH could improve treatment measures in the preoperative and postoperative periods and help in accurate guidance of rehabilitation. We investigated the characteristics of cognitive impairment according to the location of aneurysmal SAH by using the minimental state examination (MMSE), computerized neuropsychological test (CNT, Maxmedica, Seoul, Korea), and Beck depression inventory (BDI).

\section{MATERIALS AND METHODS}

\section{Subjects}

From January 2008 until December 2010, 665 patients with SAH were admitted to the Department of Neurosurgery, Kyung Hee University Hospital at Gangdong, Korea. Within this group, 211 were patients transferred to the Department of Physical Medicine and Rehabilitation after becoming neurologically stable following aneurysmal SAH. A group of 149 patients was chosen from a pool of 211 patients with solitary aneurysms that had undergone clipping of ruptured aneurysms. Twenty four patients out of the

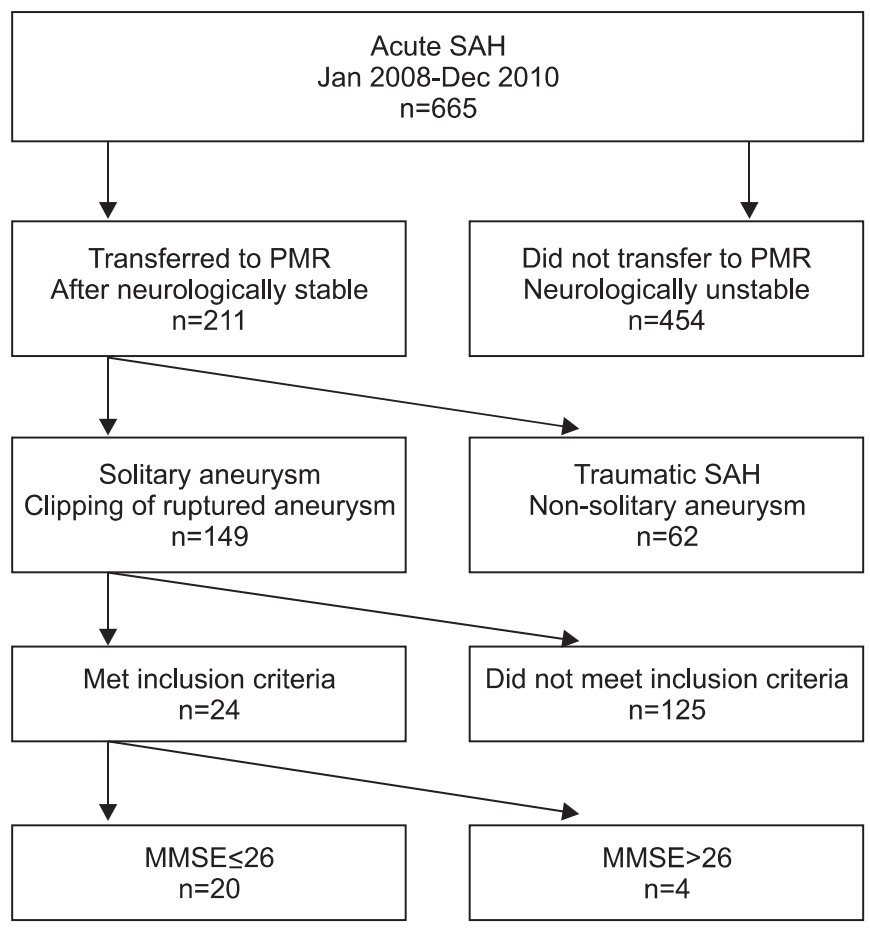

Fig. 1. Patient flow diagram. The 20 patients included in the study were among 211 patients transferred to the Department of Physical medicine and rehabilitation (PMR) after becoming neurologically stable after aneurysmal SAH. A total of 149 patients had solitary aneurysms that had undergone clipping of ruptured aneurysms. A group of 125 patients did not meet the study's inclusion criteria, and 4 patients scored $>26$ on MMSE. SAH: subarachnoid hemorrhage, PMR: physical medicine and rehebilitation.

149 met the following inclusion criteria: experience of spontaneous SAH from the rupture of the solitary nongiant aneurysm; aneurysm totally excluded by surgically placing a clip on the aneurysm's neck as confirmed on the control angiography; no major postoperative complications; good outcome after the surgery (grade 4 and 5 on Glasgow outcome scale); and no neurological or psychiatric disease before or after the surgery. The 24 patients participated in a screening test using the minimental state examination (MMSE) and 20 patients who scored $<26$ were included in the study (Fig. 1). The 20 patients were divided into 2 groups; ACoA aneurysmal SAH patients $(n=11)$ and non-ACoA aneurysmal SAH patients $(n=9)$. Eleven patients had ACoA aneurysms, and the other 9 had middle cerebral, internal carotid, or posterior communicating artery aneurysms. The median age of ACoA aneurysmal SAH patients was $48.3 \pm 11.7$ 
years, and the median age of non-ACoA aneurysmal SAH patients was $54.0 \pm 12.3$ years.

\section{Methods}

Twenty patients who scored $<26$ on MMSE were followed prospectively with BDI and CNT. The BDI is a 21 question multiple choice self-report inventory. The CNT is composed of 5 parts: verbal memory test, visual memory test, attention test, visuo-motor coordination trail-making test, and higher-order cognitive capacity test. The verbal memory test consists of a digit span and verbal learning test. Digit span consists of a forward digit span in which the patient repeats the number stated by a computer and the verbal learning test in which the patient recalls 15 words and repeats them 5 times. The visual memory test consists of a visual span test, and a visual learning test. The visual span test consists of a forward visual span test recalling the order of 9 circles on a computer screen, and backward visual span test recalling the order in reverse. The visual learning test recalls 15 different figures on a computer screen, and repeats them 5 times. The attention test consists of an auditory continuous performance test (CPT), auditory controlled CPT, visual CPT, and visual controlled CPT. Auditory CPT is a test in which the patient pushes a button whenever the patient hears the number 3 , and the auditory controlled CPT is a test in which the patient pushes the button whenever the patient hears the number 3 continuously. Visual CPT records the response time of the patient pushing the button upon seeing the number 3 on the computer screen, and visual controlled CPT records the response time of the patient pushing the button upon seeing the number 3 several times. Scores of each subtest on CNT were analyzed according to the location of the aneurysmal SAH.

\section{Statistical analyses}

Differences in demographic characteristics (age, education level), mean initial test time after SAH, Hunt and Hess grade, MMSE, BDI, and CNT between the 2 groups of subjects were tested using the Mann-Whitney U test. A Chi-square test was performed to analyze differences related to inter-group gender and Fisher grade. All tests were performed using the Statistical Package for Social Science, version 12.0 for Windows. $\mathrm{p}<$ 0.05 was considered statistically significant.

\section{RESULTS}

We assessed whether demographic characteristics (age, gender, education level) and severity of SAH (Hunt and Hess grade, Fisher grade) were different between the 2 groups. Eleven patients had ACoA aneurysm and the other 9 had non-ACoA aneurysm. The 11 ACoA aneurysmal SAH patients consisted of 5 males (45.4\%) and 6 females (54.5\%). The non-ACoA aneurysmal SAH group was comprised of 3 males (33.3\%) and 6 females (66.6\%). The median duration of formal education of the patients with ACoA aneurysmal SAH was 11.5 years (range, 9-13) and that of the non-ACoA aneurysmal SAH patients was 11.8 years (range, 9.5-14.0). The Hunt and Hess grade of patients with ACoA aneurysmal SAH was 2.77 and that of non-ACoA aneurysmal SAH patients was 2.88 . The degree of SAH was mostly severe (grade 4 on the Fisher grade); one patient was grade 3, and 10 were grade 4 in those with ACoA aneurysmal SAH. In nonACoA aneurysmal SAH patients, one patient was grade 3 and 8 were grade 4 . The mean initial test time after $\mathrm{SAH}$ with ACoA aneurysmal SAH was $36.3 \pm 1.8$ and that of non-ACoA aneurysmal SAH patients was $38.6 \pm 2.2$. The initial tests (MMSE, BDI, CNT) were performed when the patients became neurologically stable after neck clipping of ruptured aneurysms. There were no differences in age, education, mean initial test time after SAH, Hunt and Hess grade, and Fisher grade between the patients with ACoA aneurysmal SAH compared to other aneurysmal SAH ( $>0.05)$ (Table 1).

The BDI and CNT were applied to all patients. In patients with ACoA aneurysmal SAH, the BDI score was $1.3 \pm 2.1$ and that of non-ACoA aneurysmal SAH patients was $3.5 \pm 1.8$. Patients with ACoA aneurysmal SAH had significantly lower scores in BDI $(p=0.02)$. In CNT, severe neuropsychological dysfunctions across all cognitive domains including verbal memory test, visual memory test, and attention test were found in both groups. In verbal memory tests, all scores of digit span and verbal learning test were lower in patients with ACoA aneurysmal SAH. The scores of forward digit span $(p=0.001)$, backward digit span $(p=0.012)$, and first $(p<0.001)$, second $(p=0.002)$, third trial $(p=0.012)$, blocking $(\mathrm{p}=0.001)$, recall $(\mathrm{p}<0.001)$ in the verbal learning test were significantly lower in patients with ACoA aneurysmal SAH. In the attention test, patients with non- 
Table 1. Characteristics of the 20 SAH Patients

\begin{tabular}{|c|c|c|c|}
\hline Characteristics & $\begin{array}{c}\text { ACoA SAH } \\
(n=11)\end{array}$ & $\begin{array}{c}\text { Non-ACoA SAH } \\
(n=9)\end{array}$ & p-value \\
\hline Age (years) & $48.3 \pm 11.7$ & $54.0 \pm 12.3$ & $0.17^{*}$ \\
\hline Gender & & & $0.58^{\dagger}$ \\
\hline Male & $5(45.4 \%)$ & $3(33.3 \%)$ & \\
\hline Female & $6(54.5 \%)$ & $6(66.6 \%)$ & \\
\hline Educational level (years) & $11.5 \pm 1.9$ & $11.8 \pm 2.1$ & $0.92^{*}$ \\
\hline Mean initial test time after SAH, (days) & $36.3 \pm 1.8$ & $38.6 \pm 2.2$ & $0.79 *$ \\
\hline Hunt and Hess grade & $2.8 \pm 0.4$ & $2.9 \pm 0.7$ & $0.89^{*}$ \\
\hline Severity of SAH (Fisher grade) & & & $0.88^{\dagger}$ \\
\hline 1 (no subarachnoid blood) & $0(0 \%)$ & $0(0 \%)$ & \\
\hline 2 (diffuse blood) & $0(0 \%)$ & $0(0 \%)$ & \\
\hline 3 (localized clot or thicker layer) & $1(9.0 \%)$ & $1(11.1 \%)$ & \\
\hline 4 (intraparenchymal or ventricular clot) & $10(91.0 \%)$ & $8(88.8 \%)$ & \\
\hline MMSE & $12.8 \pm 5.8$ & $13.8 \pm 6.7$ & $0.28^{*}$ \\
\hline BDI & $1.3 \pm 2.1$ & $3.5 \pm 1.8$ & $0.02^{*, *}$ \\
\hline
\end{tabular}

Values are mean \pm standard deviation

ACoA: Anterior communicating artery, SAH: Subarachnoid hemorrhage, MMSE: Mini-mental state examination, BDI: Beck depression inventory

${ }^{*}$ Differences were tested using Mann-Whitney test, ${ }^{\dagger}$ Differences were tested using Chi-square test, ${ }^{*} \mathrm{p}<0.05$; Comparison between ACoA \& non-ACoA aneurysmal SAH

ACoA aneurysmal SAH took significantly more time in auditory $(\mathrm{p}=0.025)$ and visual continuous performance tests $(\mathrm{p}=0.028)$ (Table 2).

\section{DISCUSSION}

The persistence of cognitive dysfunction after aneurysmal SAH can have a profound influence on the rehabilitation process, and social and occupational reintegration of patients. Patients may experience deficits in executive functions, memory, psychomotor speed, attention, visuospatial abilities, and other cognitive domains. $^{8,20,21}$

Knowledge of the factors underlying cognitive impairments with SAH is important to tailor rehabilitation programs with respect to the specific needs. Although it is an important clinical problem, relatively little is known about the precise cause of cognitive impairment after $\mathrm{SAH} .{ }^{20}$ Current understanding of the pathogenesis of cognitive impairment after SAH is particularly hindered by the diversity of neurological insults. The typical pattern of mild-to-moderate dysfunction across multiple cognitive domains has been thought to reflect diffuse injury caused by ictal intracranial circulatory arrest ${ }^{17,22}$ and exposure of the brain to subarachnoid blood. ${ }^{20}$

Subarachnoid blood and its toxic products are thought to be one of the primary factors for cognitive dysfunction..$^{20,23}$ Other studies of cognitive outcome after SAH have identified intracerebral and intraventricular hemorrhage, ${ }^{17}$ hydrocephalus, ${ }^{17}$ delayed cerebral ischemia or infarction, ${ }^{17,24,25}$ and aneurysm location ${ }^{25,26}$ as risk factors for domain-specific cognitive dysfunction. The surgical treatment itself may also be a potential cause of local structural brain damage, because patients having endovascular treatment for ruptured aneurysms have more favorable cognitive outcomes than those who have their aneurysms surgically clipped. ${ }^{27,28}$

Many investigators have evaluated the effect of aneurysm location on cognitive function after SAH,,$^{17,22-26,29}$ but few have reported a significant association; aneurysms of the anterior communicating artery ${ }^{29}$ vertebrobasilar system, ${ }^{25}$ and left anterior circulation ${ }^{26}$ have previously been associated with poor cognitive outcome.

Quantitative measures of cognition, which are administered using a uniform procedure and are interpreted in relation to the normal range of scores, are informative for 
Table 2. Comparison of CNT Scores According to Location of Aneurysmal SAH

\begin{tabular}{|c|c|c|c|}
\hline Tests & ACoA SAH & $\begin{array}{c}\text { Non-ACoA } \\
\text { SAH } \\
\end{array}$ & p-value \\
\hline \multicolumn{4}{|c|}{ Verbal memory tests (score) } \\
\hline \multicolumn{4}{|l|}{ Digit span } \\
\hline Forward & 4.9 & 5.2 & $0.001^{*}$ \\
\hline Backward & 3.1 & 4.7 & $0.012^{*}$ \\
\hline \multicolumn{4}{|l|}{ Verbal learning test } \\
\hline $\mathrm{Al}\left(1^{\mathrm{st}}\right.$ trial $)$ & $2.3^{*}$ & 4.7 & $0.000^{*}$ \\
\hline $\mathrm{A} 2\left(2^{\text {nd }}\right.$ trial $)$ & 3.5 & 5.6 & $0.002^{*}$ \\
\hline $\mathrm{A} 3\left(3^{\text {rd }}\right.$ trial $)$ & 4.2 & 6.0 & $0.012^{*}$ \\
\hline A4 $\left(4^{\text {th }}\right.$ trial $)$ & 5.2 & 6.6 & 0.095 \\
\hline A5 $\left(5^{\text {th }}\right.$ trial $)$ & 5.6 & 6.8 & 0.095 \\
\hline B1 (interference) & 3.4 & 4.5 & 0.056 \\
\hline Blocking & 4.3 & 6.5 & $0.001^{*}$ \\
\hline Recall & 3.1 & 5.5 & $0.000^{*}$ \\
\hline Recognition & 5.9 & 7.5 & 0.067 \\
\hline \multicolumn{4}{|c|}{ Visual memory test (score) } \\
\hline \multicolumn{4}{|l|}{ Visual span } \\
\hline Forward & 4.8 & 4.7 & 0.941 \\
\hline Backward & 4.2 & 4.3 & 0.882 \\
\hline \multicolumn{4}{|l|}{ Visual learning test } \\
\hline $\mathrm{Al}\left(1^{\mathrm{st}}\right.$ trial $)$ & 5.4 & 4.2 & 0.261 \\
\hline $\mathrm{A} 2\left(2^{\text {nd }}\right.$ trial $)$ & 5.6 & 4.3 & 0.201 \\
\hline A3 $\left(3^{\text {rd }}\right.$ trial $)$ & 6.1 & 5.0 & 0.152 \\
\hline A4 $\left(4^{\text {th }}\right.$ trial $)$ & 6.1 & 5.1 & 0.175 \\
\hline A5 $\left(5^{\text {th }}\right.$ trial $)$ & 5.9 & 4.9 & 0.230 \\
\hline Recognition & 4.2 & 4.1 & 0.941 \\
\hline \multicolumn{4}{|l|}{ Attention test (sec) } \\
\hline Auditory CPT & 0.64 & 0.91 & $0.025^{*}$ \\
\hline $\begin{array}{l}\text { Auditory controlled } \\
\text { CPT }\end{array}$ & 0.61 & 0.67 & 0.968 \\
\hline Visual CPT & 0.52 & 0.84 & $0.028^{*}$ \\
\hline Visual controlled CPT & 0.56 & 0.71 & 0.497 \\
\hline
\end{tabular}

${ }^{*} \mathrm{p}<0.05$, Comparison between ACoA \& non-ACoA aneurysmal SAH

clinical and investigative purposes. CNT is performed by computer, and inter-rater reliability and validity is better than other conventional tests. Grading and recording errors may occur using conventional neuropsychological tests by environment and examiner, whereas CNT accurately collects data regardless of the differences of environment and skill of the examiner, with the addition of safely storing the data. ${ }^{30}$ Therefore, CNT could be administered to characterize a patient's general cognitive functioning and to determine the magnitude of cognitive sequelae. We included patients with mild cognitive impairments, and patients with ACoA aneurysmal SAH were associated with worse performance in the verbal learning test. In contrast, patients with non-ACoA aneurysmal SAH showed worse performance in auditory $(\mathrm{p}=0.025)$ and visual continuous performance tests $(\mathrm{p}=0.028)$.

In cases of SAH from ACoA aneurysm rupture, it has been proposed that damage to specific regions of the brain may be responsible for the cognitive deficits. 16 In ACoA patients, the most important target areas of damage are the basal forebrain, the nucleus basalis of Meynert, and neighboring structures (medial septum, diagonal band of Broca, ventral striatum). The basal forebrain is a center of cholinergic innervations for the neocortex which plays a crucial role in memory functions, predominantly in learning and spontaneous recall of new information. ${ }^{16,31}$ It is well known from dementia research that damage or degeneration in the basal forebrain profoundly reduces the levels of acetylcholine and choline acetyltransferase in the neocortex. ${ }^{32}$ The resulting cholinergic depletion deprives the hippocampal formation and other areas relevant to memory functions from cholinergic innervations, causing severe and permanent amnesia. ${ }^{33}$ This was also confirmed in our group of patients, because patients with ACoA aneurysmal SAH scored lower in all domains of verbal memory tests compared to patients with nonACoA aneurysmal SAH.

Several limitations of this study deserve mention. A clear limitation of our study was the small and selected number of patients, which precluded generalization of the results and could not explain the role of different clinical factors and treatment modalities. Second, our results may not be applicable to more severely disabled SAH patients who cannot undergo CNT. Also, risk factors that we have not identified may be important for producing more severe levels of cognitive impairments after SAH. Although CNT is sensitive to subtle cognitive impairments, there is a need to develop cognitive tests that are more easily administered and widely applicable to more severely impaired SAH patients. Longitudinal studies with larger numbers of patients exhibiting a more 
diverse clinical course and receiving different types of treatment are also needed.

\section{CONCLUSION}

The cognitive deficit following aneurysmal SAH could be characterized by its location using CNT. In patients with ACoA aneurysmal SAH, scores of the verbal memory test were significantly lower than scores of patients with ACoA aneurysmal SAH, and auditory CPT, visual CPT test were higher. Using CNT in patients with aneurysmal SAH could be a useful tool in evaluating the characteristics of cognitive impairment and planning rehabilitation programs according to each characteristic.

\section{REFERENCES}

1. Donnan GA, Fisher M, Macleod M, Davis SM. Stroke. Lancet 2008; 371: 1612-1623

2. Rooij de NK, Linn FHH, Plas van der JA, Algra A, Rinkel GJE. Incidence of subarachnoid haemorrhage: a systematic review with emphasis on region, age, gender and time trends. J Neurol Neurosurg Psychiatry 2007; 78: 1365-1372

3. Nieuwkamp DJ, Setz L, Algra A, Linn FHH, Rooij de NK, Rinkel GJE. Changes in case fatality of aneurysmal subarachnoid haemorrhage over time, according to age, sex, and region: a meta-analysis. Lancet Neurology 2009; 8: 635-642

4. Wilde MC. Neuropsychological outcome in subarachnoid hemorrhage due to aneurysm. Crit Rev Physic Rehab Med 2006; 18: 117-131

5. Visser-Meily JMA, Rhebergen ML, Rinkel GJE, Zandvoort van MJ, Post MWM. Long-term health related quality of life after aneurysmal subarachnoid hemorrhage; relationship with psychological symptoms and personality characteristics. Stroke 2009; 40: 1526-1529

6. Fertl E, Killer M, Eder H, Linzmayer L, Richling B, Auff E. Long-term functional effects of aneurysmal subarachnoid haemorrhage with special emphasis on the patient's view. Acta Neurochir 1999; 141: 571-577

7. Morris PG, Wilson JT, Dunn L. Anxiety and depression after spontaneous subarachnoid hemorrhage. Neurosurgery 2004; 54: 47-54

8. Kreiter KT, Copeland D, Bernardini GL, Bates JE,
Peery S, Claassen J, Du YE, Stern Y, Connolly ES, Mayer SA. Predictors of cognitive dysfunction after subarachnoid hemorrhage. Stroke 2002; 33: 200-209

9. Tidswell P, Dias PS, Sagar HJ, Mayes AR, Battersby RD. Cognitive outcome after aneurysm rupture: relationship to aneurysm site and perioperative complications. Neurology 1995; 45: 875-882

10. Stenhouse LM, Knight RG, Longmore BE, Bishara SN. Long-term cognitive deficits in patients after surgery on aneurysms of the anterior communicating artery. J Neurol Neurosurg Psychiatry 1991; 54: 909-914

11. Talland GA, Sweet WH, Ballantine HT Jr. Amnestic syndrome with anterior communicating artery aneurysm. J Nerv Ment Dis 1967; 145: 179-192

12. Volpe BT, Hirst W. Amnesia following the rupture and repair of an anterior communicating artery aneurysm. J Neurol Neurosurg Psychiatry 1983; 46: 704-709

13. Damasio AR, Graff-Radford NR, Esling PJ, Damasio H, Kassell N. Amnesia following basal forebrain lesions. Arch Neurol 1985; 42: 263-271

14. Phillips S, Sangalang V, Sterns G. Basal forebrain infarction. A clinicopathologic correlation. Arch Neurol 1987; 44: 1134-1138

15. Alexander MP, Freedman M. Amnesia after anterior communicating artery aneurysm rupture. Neurology 1984; 34: 752-757

16. DeLuca J. Cognitive dysfunction after aneurysm of the anterior communicating artery. J Clin Exp Neuropsychol 1992; 14: 924-934

17. Ogden JA, Mee EW, Henning M. A prospective study of impairment of cognition and memory and recovery after subarachnoid hemorrhage. Neurosurgery 1993; 33: $572-587$

18. Laiacona M, De Santis A, Barbarotto R, Basso A, Spagnoli D, Capitani E. Neuropsychological followup of patients operated for aneurysms of anterior communicating artery. Cortex 1989; 25: 261-273

19. Bottger S, Prosiegel M, Steiger H, Yassouridis A. Neurobehavioural disturbances, rehabilitation outcome, and lesion site in patients after rupture and repair of anterior communicating artery aneurysm. J Neurol Neurosurg Psychiatry 1998; 65: 93-102

20. Hutter BO, Kreitschmann-Andermahr I, Mayfrank L, Rohde V, Spetzger U, Gilsbach JM. Functional outcome after aneurysmal subarachnoid hemorrhage. Acta Neurochir Suppl (Wien) 1999; 72: 157-174 
21. Hillis A, Anderson N, Sampath P, Rigamonit D. Cognitive impairments after surgical repair of ruptured and unruptured aneurysms. J Neurol Neurosurg Psychiatry 2000; 69: 608-615

22. Grote E, Hassler W. The critical first minutes after subarachnoid hemorrhage. Neurosurgery 1988; 22: 654-661

23. Hutter BO, Kreitschmann-Andermahr I, Gilsbach J. Cognitive deficits in the acute stage after subarachnoid hemorrhage. Neurosurgery 1998; 43: 10541064

24. Vilkki J, Holst P, Ohman J, Servo A, Heiskanen O. Social outcome related to cognitive performance and computed tomographic findings after surgery for a ruptured intracranial aneurysm. Neurosurgery 1990; 26: 579-584

25. Richardson JT. Cognitive performance following rupture and repair of intracranial aneurysm. Acta Neurol Scand 1991; 83: 110-122

26. Stabell KE, Magnaes B. Neuropsychological course after surgery for intracranial aneurysms: a prospective study and a critical review. Scand J Psychol 1997; 38: 127-137

27. Bellebaum C, Schafers L, Schoch B, Wanke I, Stolke D, Forsting M, Daum I. Clipping versus coiling: neuropsychological follow up after aneurismal subarachnoid hemorrhage (SAH). J Clin Exp Neuropsychol 2004; 26: 1081-1092

28. Fontanella M, Perozzo P, Ursone R, Garbossa D, Bergui M. Neuropsychological assessment after microsurgical clipping or endovascular treatment for anterior communicating artery aneurysm. Acta Neurochir (Wien) 2003; 145: 867-872

29. Bornstein RA, Weir BK, Petruk KC, Disney LB. Neuropsychological function in patients after subarachnoid hemorrhage. Neurosurgery 1987; 21: 651-654

30. Kim YH, Shin SH, Park SH, Ko MH. Cognitive assessment for patient with brain injury by computerized neuropsychological test. J Korean Acad Rehab Med 2001; 25: 209-216

31. Dunker RO, Harris AB. Surgical anatomy of the proximal anterior cerebral artery. J Neurosurg 1976; 44: 359-367

32. Whitehouse PJ, Price DL, Clark AW, Coyle JT, DeLong MR. Alzheimer disease: evidence for selective loss of cholinergic neurons in the nucleus basalis. Ann Neurol 1981; 10: 122-126

33. Kopelman MD. The cholinergic neurotransmitter system in human memory and dementia: a review. Q J Exp Psychol A 1986; 38: 535-573 